Vol. 4, No. 2, 2018

Yakov Nemyrovskyi ${ }^{1}$, Eduard Posvyatenko ${ }^{2}$, Sergey Sheikin ${ }^{3}$, Yuriy Tsekhanov ${ }^{4}$

1. Department of Metal Cutting Machines and Systems, Central Ukrainian National Technical University, Ukraine, Kropyvnyts'kyy, Prospekt Universytetskyi, 8, E-mail: provotorova1951@gmail.com 2. Department of Production, Repair and Materials Science, National Transport University, Ukraine, Kiev, M. Omelianovycha-Pavlenka Str., 1, E-mail: natali1963@ukr.net

3. Department of Perspective, Resource-saving Processing Technologies, V. Bakul Institute for Superhard Materials of the National Academy of Sciences of Ukraine, Ukraine, Kiev, Avtozavodskaya Str., 2, E-mail: sheykin2003@ukr.net

4. Department of Informatics and Graphics, Voronezh State Technical University, Russia, Voronezh, Moskovsky av., 14, E-mail: tsekhanov@yandex.ru

\title{
CYLINDRICAL CONTROL OF HOLES OF TUBE DETAILS MANUFACTURED BY DEFORMING BROACHING
}

Received: July 14, 2018 / Revised: September 12, 2018 / Accepted: December 26, 2018

(C) Nemyrovskyi Ya., Posvyatenko E., Sheikin S., Tsekhanov Yu,. 2018

Abstract. This work is devoted to the issues of processing holes in different thickness of tubular billets great length deforming broaching. The urgency of this problem is substantiated. The results of studying the regularities of deformation of a material in the deformation zone under deforming broaching are presented. The reasons for the formation of this type of geometric error as the curvature of the axis of the machined hole are established. They are caused by the variation of axial deformations of the sections of blanks of various thickness in the circumferential direction. An analytical-experimental model for determining the curvature of the axis of processed products is given. The factors influencing this kind of error are systematized. The main structural factors of the deforming broach are identified, which can influence this kind of error. Experimental studies were carried out to optimize the design parameters of the instrument. An experimental mathematical model is developed to determine the influence of the main constructive factors of the instrument on the change of this type of error. The conditions for minimizing the curvature of the axis of the machined hole are established. The influence of the conditions of basing the workpiece on the curvature of its axis is determined. The recommendations on the design of deforming broaches have been developed, which make it possible to ensure the alignment of the workpiece and the tool. New designs of deforming broaches have been developed, which make it possible to control the cylindricality of the treated deep holes. The results of experimental verification of the deforming broach designs developed during the processing of a pilot batch of various thickness blanks are presented.

Keywords: deforming broaching, error, workpieces different thickness, curvature of the axis, variation of axial deformations, basing errors.

\section{Introduction}

One of the main tasks of modern machine building is the development and implementation of resource-saving technologies and improving the quality indicators of processed products.

Deforming broaching is used as roughing and finishing operations, including the processes of shaping and deformation hardening.

Deformation of holes in tubular blanks of plastic materials in most cases leads to through cold deformations of the workpieces to be processed. This allows, on the one hand, to radically improve the physical and mechanical properties of the surface layer and the core of shell-type parts. On the other hand, 


\section{Cylindrical Control of Holes of Tube Details Manufactured by Deforming Broaching}

the processing of sleeve details by deforming broaching leads to a change in the geometric dimensions of the tubular blank without chip removal. This has the following positive consequences: a decrease in the non-roundness of the billet hole by one or two orders and the localization of a defective layer of metallurgical origin, which includes carbon-depleted metal, surface delaminations, for subsequent removal by cutting. This allows us to classify this operation as extremely resource-saving for metal, productivity and energy conservation.

Nowadays, the quality indicators that are provided by this process are thoroughly studied: roughness, depth and degree of cold work, the resource of plasticity used [1-3]. One of the least studied parameters of quality is accuracy.

Expanding the areas of use of deforming broaching is the ability to handle deep holes in the following nomenclature: hydraulic cylinders and pneumatic cylinders, shock absorber and oil pump cylinders, shaft racks, cardan shafts, special purpose chambers, deep pump housings, etc. This is constrained by the increased requirements for the accuracy of the shape of the processed holes in these parts, namely the deviation from cylindricality or the curvature of the axis of the processed billet is not more than $1 \mathrm{~mm}$ per $1 \mathrm{~m}$ of length tr of the exhausted part.

The study [3] notes that a serious, not always solved, problem in the deforming broaching of deep holes in the details of the type of shell is the deviation from the cylindrical nature of the treated hole.

This type of geometrical error (Fig. 1) is caused by the bending of the workpiece, caused by its initial different thickness. The smallest and largest wall thicknesses in the cross section of the pipe are determined by the tolerance for the thickness of its wall. This tolerance according to GOST 8732-70 for hot-rolled pipes varies from $+10 \%$ to $-12.5 \%$, and in accordance with GOST $8734-75$ for cold-drawn pipes from $+10 \%$ to $-10 \%$.

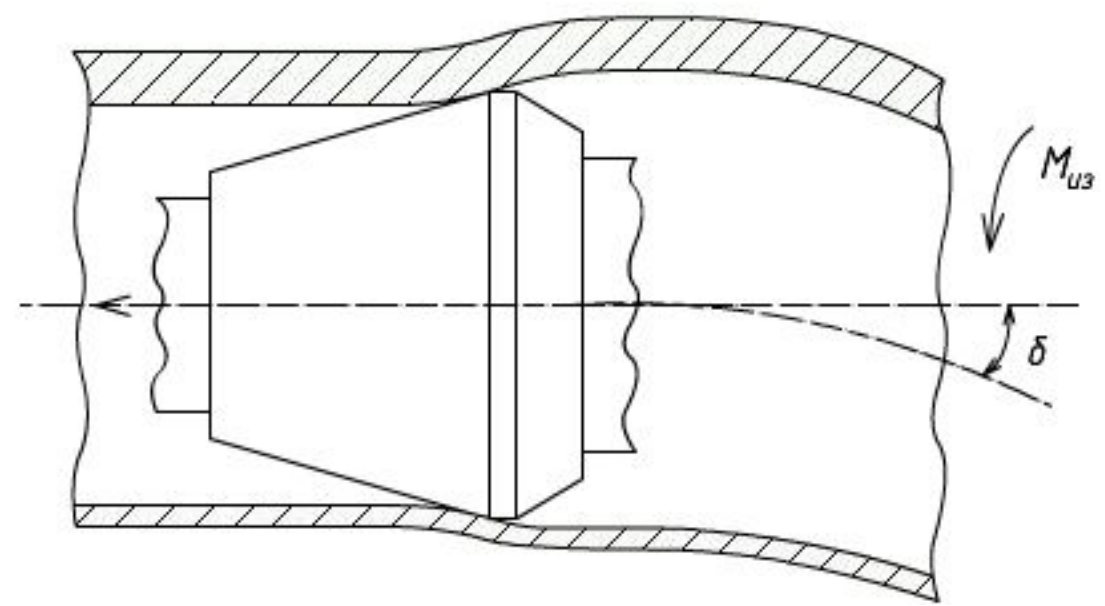

Fig. 1. Curvature of the axis of the processed workpiece

Effective methods to combat this error are absent. The authors of [4] propose to apply an additional editing operation for such products, but note the appearance after it of a new type of "facet" error.

Thus, it becomes obvious that for effective introduction and application in the industry of a highperformance deforming broaching process for processing deep holes in tubular billets, a detailed study of the problem of ensuring the cylindrical nature of the processed products is necessary.

\section{Review of Modern Information Sources on the Subject of the Paper}

It is known [5] that the most accurate scheme of the deformation center under deforming pulling is the scheme according to which the deformation center includes the contact zone and two non-contact zones connected with it (Fig. 2).

Our investigations [6] established the regularities of the flow of material in the deformation region (Fig. 3), namely: in the contact zone, the deformation power has a well-defined minimum at the coefficient of axial deformation $\mathrm{K}=0.5$ (curve 3 , curve 2), so the process deformation is stable. 


\section{Yakov Nemyrovskyi, Eduard Posvyatenko, Sergey Sheikin, Yuriy Tsekhanov}

In non-contact zones, the minimum power corresponds to a wide range of variation of the coefficient $\mathrm{K}=0.4-2.3$ (Fig. 3, curves 1-3), i.e. The kinematic parameters in these zones have a greater number of degrees of freedom. Therefore, the process of deformation in them has a clearly pronounced unstable character.

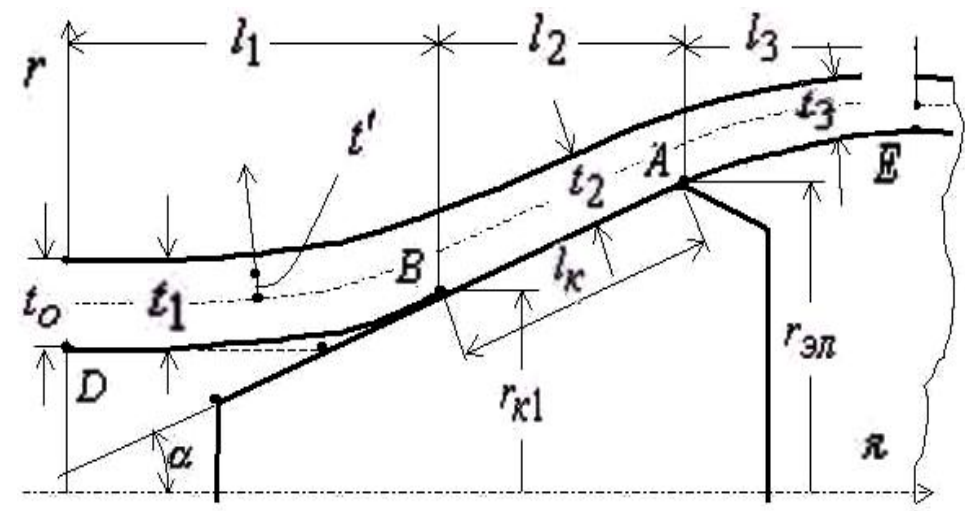

Fig. 2. Scheme of plastic deformation region

On the basis of this conclusion, an important scientific and technological position is justified: an intensive formation of hole errors occurs in non-contact zones of the deformation focus under the influence of external perturbing factors (initial different thickness, misalignment of the part and tool, weight of the broach, etc.).

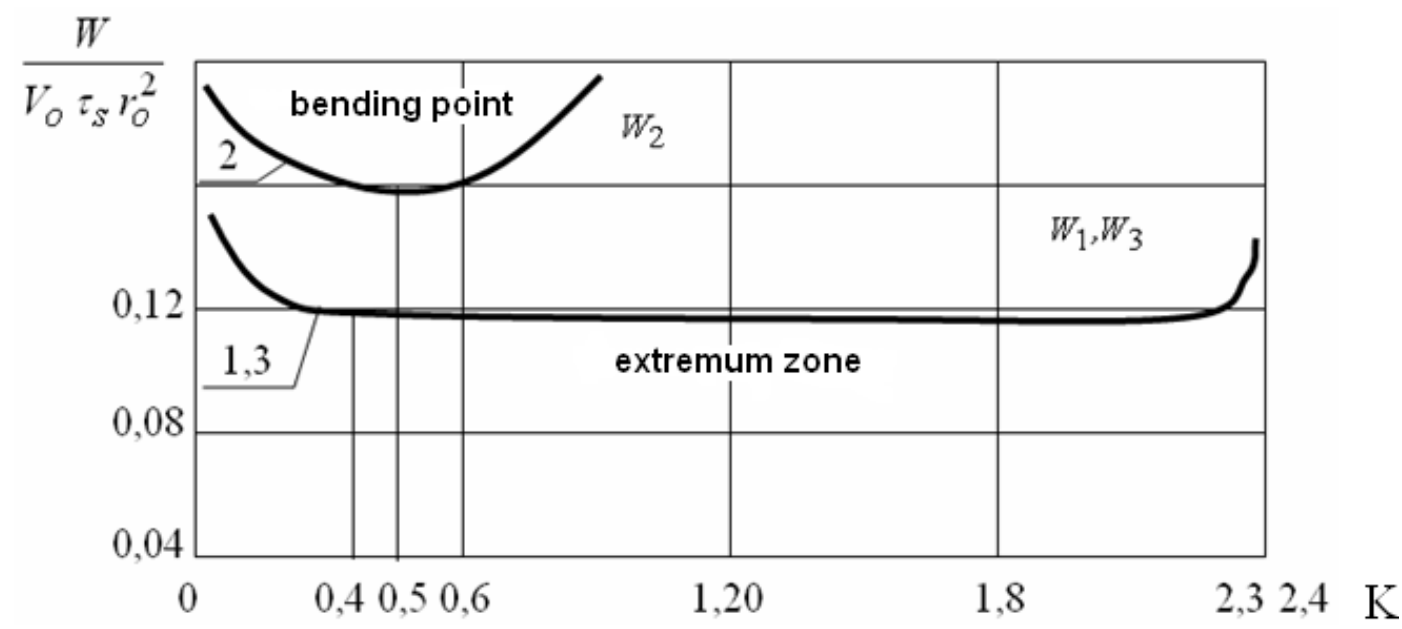

Fig. 3. The dependencies of the shape-changing plastic deformation capacities in the contact zone (2) and non-contact zones (1.3) on the parameters of axial deformation $\mathrm{K}$ at angle $\alpha=2^{\circ}, \mathrm{t} 0 / \mathrm{r} 0=0.4$

Let us consider the question of the effect of the initial heterogeneity of the billet on its axial deformations. To do this, we will study how the axial deformations of the workpiece change during its deformation. The experiments carried out by us [7] made it possible to establish the following.

Depending on the thickness of the workpiece, the tension on the element and the angle of inclination of the tool of the working tool $\alpha$, axial deformations can be of three kinds. This shortening, the absence of axial deformations and axial elongation (Fig. 4).

Therefore, when deforming various thickness blanks, each of the longitudinal sections of a pipe of different cross-section varies its length in different ways. Variations of axial deformations of sections of workpieces of various thicknesses in the circumferential direction are shown in Fig. 5.

This behaviour causes such a kind of geometric error as the axial curvature or deviation from cylindricality. 


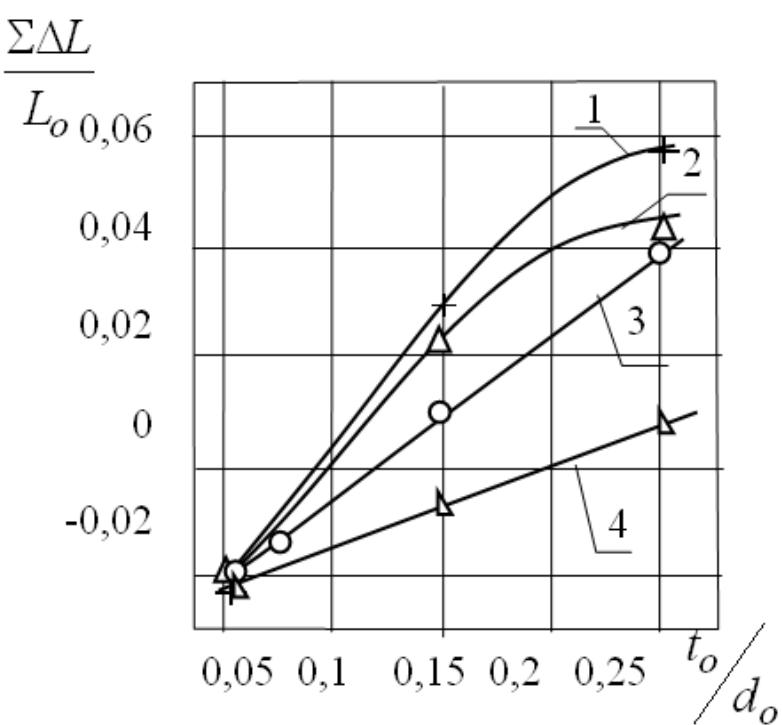

Fig. 4. The dependence between the total change in the component length and the relative thickness of the wall $\left(\mathrm{d} 0=40 \mathrm{~mm}, \mathrm{a} / \mathrm{d} 0=0.125, \Sigma \mathrm{a} / \mathrm{d} 0=0.075\right.$, angle $\alpha: 12^{\circ}(1)$, $8^{\circ}(2), 4^{\circ}(3), 2^{\circ}(4)$; material is steel 20$)$

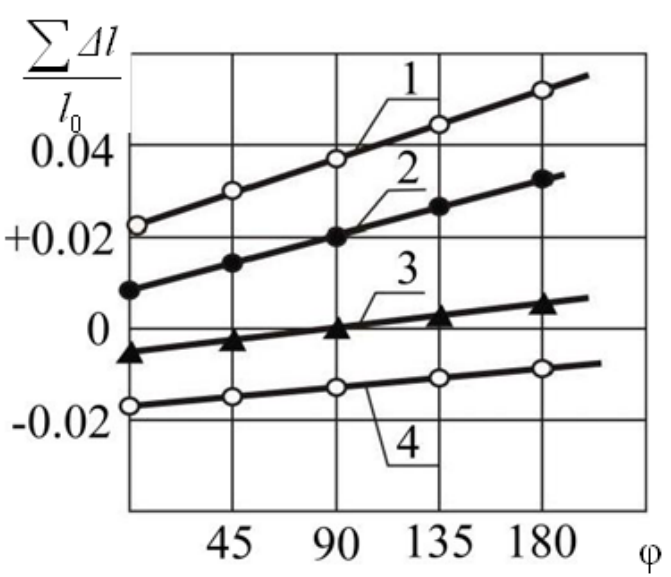

Fig. 5. Variations in axial deformation values in the cross section of the processed workpiece $(\mathrm{a} / \mathrm{d} 0=0.025$ at angle $\alpha$ : $\mathrm{t} \min =0.1, \varphi=0 ; \mathrm{t} \max =0.15, \varphi=180 . \alpha: 1-12^{\circ}$, $2-8^{\circ}, 3-4^{\circ}, 4-2^{\circ}$; material is steel 20)

To quantify this error, in [8] the model developed for determining the bending of the axis of the deformed part $f$ as a function of the change in the axial dimension of thin-walled and thick-walled sections. As follows from [8], the bending of the axis is determined from expression (1), obtained according to Fig. 6.

$$
f=\left[\frac{L_{0}+0.5\left(\Delta l_{\max }+\Delta l_{\min }\right) D}{\Delta l_{\max }-\Delta l_{\min }}\right]\left[1-\cos \frac{\left(\Delta l_{\max }+\Delta l_{\min }\right)}{2 D}\right] .
$$

The entry values of the dependency (1), $\Delta l_{\max }$ and $\Delta l_{\min }$, are maximum and minimum changes in the length of the thin-walled and the thick-walled areas obtained from the experiments given in Fig. 4.

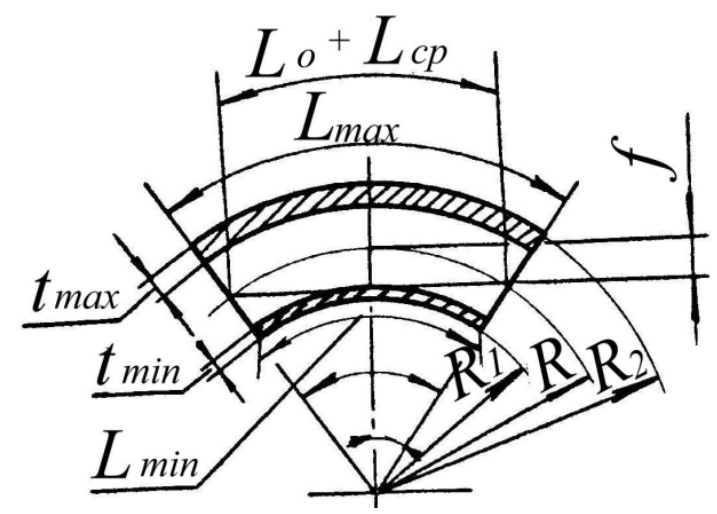

Fig. 6. Axial camber of the component with different thickness

The performed calculations using this model have shown that it is possible to influence the bending of the axis of the workpiece by changing the angle $\alpha$ and the tension by the element $-a$. The optimal position from the minimization of this type of error is the use of deforming elements with angles $\alpha=1-2^{\circ}$ and the maximum allowable interference per element. These recommendations should be taken into account when designing a tool for processing deep holes in tubular billets.

Obviously, the possibility of developing optimal designs of deforming broaches will allow us to control this kind of geometric error, like the bending of the axis of the manufactured hole of a tubular part of considerable length. 


\section{Yakov Nemyrovskyi, Eduard Posvyatenko, Sergey Sheikin, Yuriy Tsekhanov}

\section{Objectives and Problems of Research}

Development of a methodology for designing optimal designs of deforming broaches, which will allow to control the cylindricality of deep holes of manufactured tubular parts.

\section{Problem Statement}

Analysis of the above material showed that this kind of geometric error as the curvature of the axis is formed both in the contact and in the non-contact zones of the deformation focus and due to the instability of the material flow in them, as well as the influence of the initial error of the workpiece and the errors of its basing.

Imagine the influence of regime factors, tool geometry, external perturbing factors on the error parameter - deviation from cylindricality in the form of a circuit (Fig. 7).

This scheme makes it possible to determine the basic constructive factors of the tool that will allow to influence this kind of geometrical error. In turn, this will be used to create the optimal design of the deforming broach for processing deep holes.

Our investigations [9] found that deformation in different zones of the deformation focus is a single process of plastic shaping of the billet. Therefore, its perturbations in the form of the manifestation of the instability of deformation in each of the zones of the deformation focus will inevitably affect the formation of errors of the entire part. Therefore, the prevention of instability of the flow of material must be carried out in all areas of the focus, and primarily in non-contact, where, as shown in Fig. 3, the flow is unstable even in the absence of external perturbing factors.

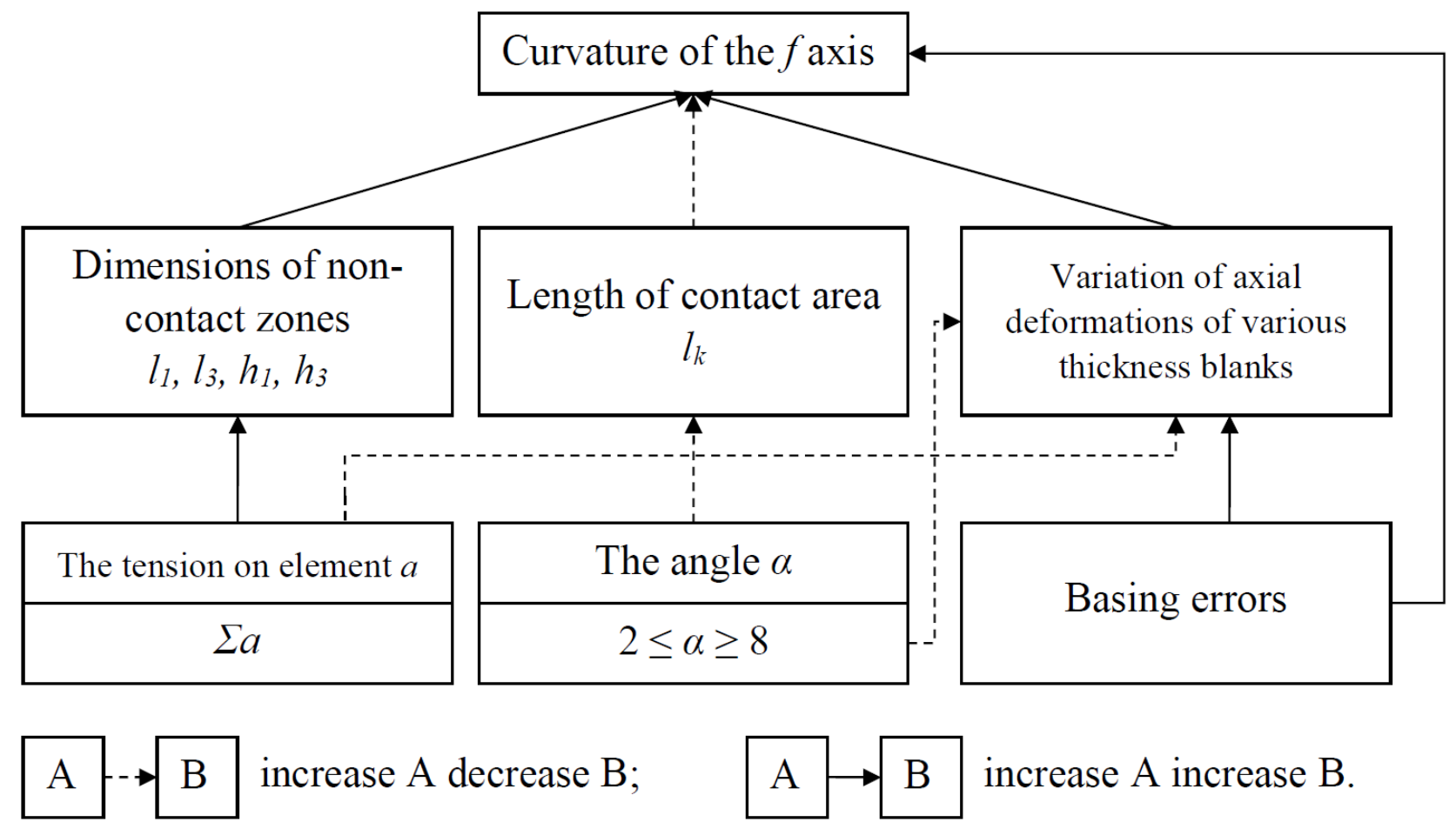

Fig. 7. The influence of technological factors, the size of the zones of the deformation focus, the error of basing, the initial error on the curvature of the axis of the processed part

As follows from the well-known laws of mechanics and stability theory, the very beginning of the manifestation or disappearance of motion instability in mechanical systems depends very strongly on the smallest manifestations of disturbing or stabilizing factors. Regarding our process, it follows that an active external technological impact, even insignificant in magnitude, on the zones of the deformation focus, especially on non-contact ones, can significantly affect the stability of the entire process of deformation, and thus reduce processing errors. 


\section{Cylindrical Control of Holes of Tube Details Manufactured by Deforming Broaching}

\section{Development of the broach construction}

Concerning our kind of geometrical error - the curvature of the axis of the manufactured part, it is necessary to note the following. This error, as follows from Fig. 7, is due to the initial heterogeneity of the workpiece and the instability of the material flow in the non-contact zones. The latter component causes the appearance of a bending moment under the influence of variations in the axial deformations of the blanks, which are thickened in the circumferential direction (Fig. 1). Therefore, it is necessary to create a stabilizing moment, which will prevent the bending of the billet axis. The first additional support with respect to which this ruling moment will act is to be placed on the plastic section of the non-contact zone, which is remote from the larger base of the working cone of the deforming element by a distance 11, which is determined according to the calculated dependence (2) obtained in [6].

$$
l_{1}=0.43 \sqrt{t_{0} d_{0}} \text {. }
$$

Another support with respect to which a stabilizing moment is created that affects the non-contact zone in front of the contact area will be the contact portion itself, in which the flow of material is of a stable nature [6].

The presence of the first support also approximates the flow conditions of the material in the noncontact zone beyond the contact area to the flow of material in the contact zone, which in itself positively affects the accuracy of the machined hole. The stabilizing moment itself will be created from the inner surface of the workpiece by special structural elements of intermediate and rear rigid cylindrical guides.

According to these provisions, we developed a variant of the design of an experimental deforming broach (Fig. 8).

The structure of this broach includes a front shank 1, made together with the stem; molding elements $2,4,5,6,7$, separated by spacers 3 , as well as additional structural elements. These elements include: an intermediate guide 8 , an auxiliary member 10 , and a rear guide 11 . The intermediate guide 8 is located behind the last roughing element 7 . The auxiliary member 10 is located at a maximum of the height of the non-contact zone from the finishing element 9 and is remote from it a distance 11 (the end of the plastic section of the non-contact zone (Figure 9)), the value of which is calculated from the dependence (2). The rear rail 11 is located behind the auxiliary member 10 .

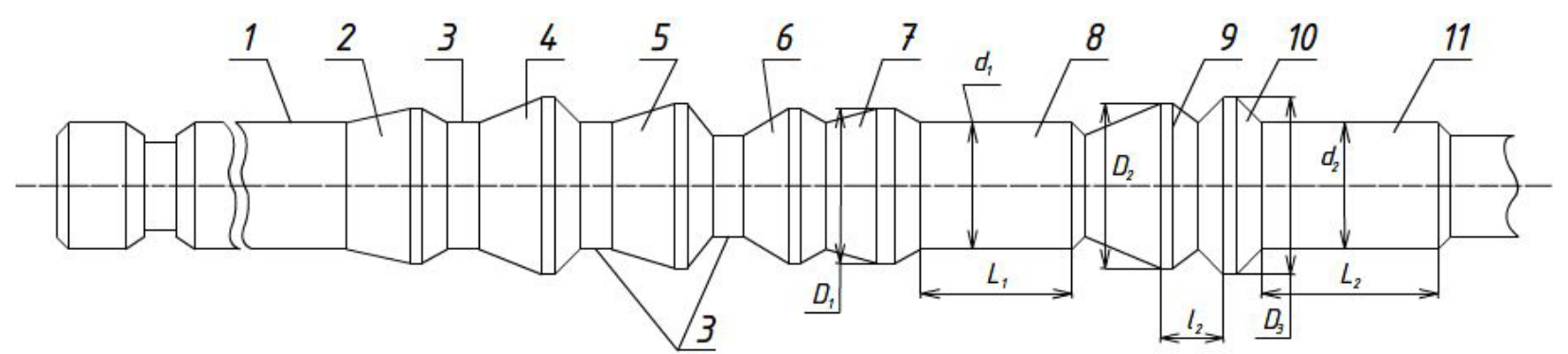

Fig. 8. The design of the experimental deforming broach

It follows from Fig. 9, a non-contact zone 3 arises behind the finishing deforming element, in which, as indicated above, there is an instability of the deformation of the material of the workpiece, which leads to an intense formation of errors. Thus, for example, this kind of error, like the curvature of the axis of the machined part, arises under the influence of the variation of the axial deformations of the tubular blanks, which are variously thickened in the circumferential direction. The dimensions of this zone are influenced by the dimensions of the workpiece $\left(d_{0}, t_{0}\right)$ and also by the interference on the element, which is determined by the difference between the hole diameter after the last roughing element 7 and the diameter of the finishing deformation element 9. Therefore, at the end of the plastic section of the non-contact zone 3 , install auxiliary element 10 , which should act as a support and stabilize the flow of material in this zone.

The coaxial intermediate guide 8 and the rear guide 11 ensure that the non-contact zones are loaded with the stabilizing moments M1 and M2, which counteract the curvature of the workpiece axis and ensure 


\section{Yakov Nemyrovskyi, Eduard Posvyatenko, Sergey Sheikin, Yuriy Tsekhanov}

the cylindricality of the machined part. The main factors affecting the accuracy of the processing by such parameters as cylindricality are the interference on the first finishing element 9, the diameter of the cylindrical ribbon of the auxiliary element 10 , and also the diameters and lengths of the intermediate and rear guides.

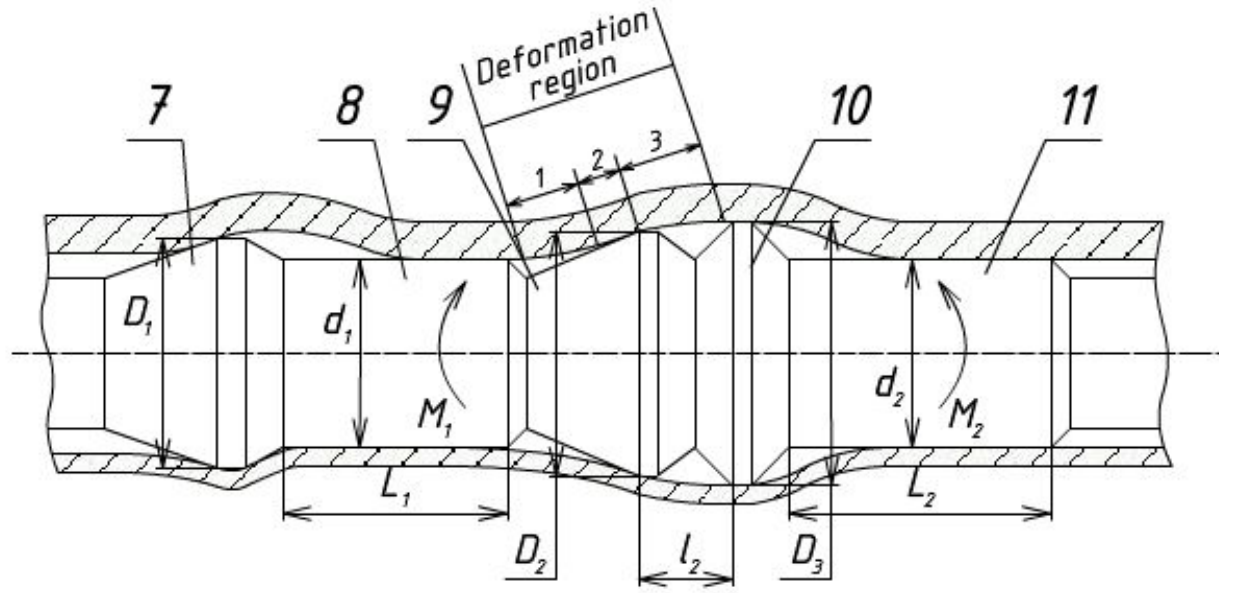

Fig. 9. Deformation of the workpiece by an experimental deforming broach

\section{Laboratory studies}

To confirm the correctness of the developed provisions and optimize the design of the instrument, by choosing the parameters of structural elements, it was decided to conduct experiments on blanks from cold-drawn pipes $56 \times 4$ GOST $8734-75$ from steel 20 GOST $8733-74$. From these pipes, billet lengths of $500-4 \mathrm{~mm}$ were cut. The outer diameter of the batch of blanks was within $54.8 \div 56.1$; the diameter of the hole is $47.64 \div 48.24$; the wall thickness is $3.28 \div 4.23$.

Measurement of the total deflection of blanks was carried out when they were installed on a special control plate. The value of the total deflection was determined by using a set of probes at the location of the maximum gap between the forming outer surface of the workpiece and the plane of the control plate. In some cases, the curvature of the axis was measured by a specially manufactured calibre, the dimensions of which will be indicated below.

The thickness difference was measured by a micrometre with a ball tip. In addition, the different thicknesses were determined from the dependence $\frac{t_{\max }-t_{\min }}{t_{c p}}$, where $t_{c p}=\frac{t_{\max }+t_{\min }}{2}$, starting from the values of $t_{\min }$ and $t_{\max }$, determined from the measurements of the inner and outer diameters of the workpiece in the corresponding cross section.

In necessary cases, according to GOST 10356-68, ellipticity of the hole was controlled. Its measurement was carried out with a gage with a measuring head (division price $0.001 \mathrm{~mm}$ ). The outer diameter was measured with a micrometre in the respective cross sections of the preform.

To eliminate the influence of different values of initial differences, all the workpieces processed were pre-machined on an eccentric mandrel, which provided a constant $1 \mathrm{~mm}$ thickness for all blanks. Those, the maximum wall thickness is $4 \mathrm{~mm}$, the minimum is $3 \mathrm{~mm}$.

The experiments were carried out on a horizontally extending machine tool. 765204 at a broaching speed of $5 \cdot 10^{-2} \mathrm{~m} / \mathrm{s}$. Broaching was carried out according to the compression scheme [4].

We conducted the following experiments. A batch of the above blanks in an amount of 5 pcs. was processed by single deforming elements according to the construction of the broach (Fig. 8). The diameters of these elements are as follows: $2-47.6 ; 4-48.0 ; 5-48.7 ; 6-49.15 ; 7-49.2 ; 8-49.51 ; 9-49.61 \mathrm{~mm}$. We call this scheme 1 .

In addition to this, 7 more batches of pre-prepared blanks were processed according to the following schemes. 


\section{Cylindrical Control of Holes of Tube Details Manufactured by Deforming Broaching}

Scheme 2. The processing was carried out with a broach on which five roughing deformers and two finishing deformers were installed, the diameters of which are indicated in the description of scheme 1. A rear guide is placed behind the last finishing element. The diameter of the guide is equal to the diameter of the last finishing deforming element $-49.61 \mathrm{~mm}$, and the length was 1.6 of the diameter of the initial hole of the workpiece, i.e. $76 \mathrm{~mm}$. The diameter of the guide was assumed equal to the diameter of the last finishing deforming element from the following considerations. If the diameter of the guide is larger than the diameter of the last element, then it will plasticize the hole, which will lead to negative consequences during its processing. When the diameters of the guide and the last element are equal, the guide works with the maximum elastic interference and does not deform the workpiece plastically. It should be noted that its diameter may be smaller than the diameter of the last deforming element, but in no case smaller than the diameter of the machined hole. That is, the guide must necessarily contact the surface of the hole in order to perform its functions. The length of the guide was established by additional experiments, which showed that with an increase in its length, the cylindricality of the hole increases and reaches its maximum with the length of the guide equal to the length of the workpiece. But a significant increase in this accuracy parameter occurs only with a guide length of approximately 1.5-2.0 of the diameter of the workpiece hole. With further increase in its length, the intensity of growth of the cylindricality of the treated hole is significantly reduced.

Scheme 3. The processing was carried out by a broach that had five roughing elements and two finishing deforming elements of the above dimensions. After the last roughing element with a diameter D1 $=49.2 \mathrm{~mm}$, an intermediate guide of the same diameter, 1.3 times the diameter of the billet hole, was installed; approximately $63 \mathrm{~mm}$. The nominal interference to the first finishing element was $0.31 \mathrm{~mm}$.

Scheme 4 . The processing was performed by a broach that had five roughing elements, one finishing deformation element with a diameter $D_{2}=49.51 \mathrm{~mm}$, intermediate and rear guides of the above dimensions.

Scheme 5. The processing was carried out with a broach on which five roughing deformers and two finishing elements were installed, the last element serving as a support at the maximum height of the noncontact zone. To do this, it was remote from the beginning of the cylindrical ribbon of the finishing deforming element to a distance calculated according to the relationship (2). Those. distance $l_{2}=5.9 \mathrm{~mm}$. In the future, the finishing deformation element located in the non-contact zone from the first finishing element will be called a special element.

The diameter of the special element was calculated according to the experimentally obtained dependence [6]:

$$
D_{\text {s.e. }}=D_{n}+\frac{t_{0}^{0.6} \sqrt{D_{n}-D_{n-1}} \cdot D_{n}^{0.12}}{4 H B^{0.35}} .
$$

Scheme 6 . The processing was performed by a broach that had six deforming elements, a special element and a rear guide.

Scheme 7. The processing was performed by a broach that had six deforming elements, a special element, and an intermediate guide.

Scheme 8 . The processing was performed by a broach that had six deforming elements, a special element, and an intermediate and a rear guide.

The results of the experiments are given in Table 1.

Analysis of the results showed that the presence of a rear guide (scheme 2), an intermediate guide (scheme 3), a special element (Scheme 5) reduces the curvature of the axis of the manufactured part and the ellipticity of the hole.

It should be noted that the efficiency of using the rear guide increases significantly when used together with a special element (Scheme 6).

An even greater effect is achieved when using combinations of these structural elements (schemes 4, 6 and 7). But the greatest effect is achieved when equipping the broach with all additional structural elements at the same time (Scheme 8, Fig. 8). 
Experimental data on obtaining the curvature of the axis and ellipticity of the hole

\begin{tabular}{|c|c|c|c|c|}
\hline \multirow{3}{*}{ The broaching scheme, № } & \multicolumn{2}{|c|}{ The curvature of the axis $f$} & \multicolumn{2}{c|}{ The ellipticity of the hole } \\
\cline { 2 - 5 } & $\begin{array}{c}\text { Average value, } \\
\mathrm{mm}\end{array}$ & $\begin{array}{c}\text { Maximum value, } \\
\mathrm{mm}\end{array}$ & $\begin{array}{c}\text { Average value, } \\
\mathrm{mm}\end{array}$ & $\begin{array}{c}\text { Maximum value, } \\
\mathrm{mm}\end{array}$ \\
\hline 1 & 6,2 & 7,4 & 0,08 & 0,11 \\
\hline 2 & 3,2 & 4.3 & 0,051 & 0.07 \\
\hline 3 & 3,1 & 3,7 & 0,048 & 0,062 \\
\hline 4 & 2,1 & 2,6 & 0,038 & 0,052 \\
\hline 5 & 3,8 & 4,5 & 0,043 & 0,056 \\
\hline 6 & 1,8 & 2,2 & 0,035 & 0,054 \\
\hline 7 & 1,9 & 2,5 & 0,04 & 0,05 \\
\hline 8 & 0,98 & 1,25 & 0,024 & 0,03 \\
\hline
\end{tabular}

It should be noted that the approximate calculation of the curvature of the axis according to the model (1) for the processing conditions ( $a / d_{0}=0.025, \sum a / d_{0} \approx 0.05, \alpha=4^{\circ}$ ) using $\Delta l_{\max }$ and $\Delta l_{\min }$ from the experimental results taken from [8] showed a good coincidence of the calculated value $f=4.9 \mathrm{~mm}$ with the experimental $f=6.2 \mathrm{~mm}$. This is approximately $20 \%$ different from the experiment (Scheme 1), which may be due to the difference in the initial data and the influence of the baseline conditions.

\section{Development of an experimental model}

To assess the influence of each factor on the magnitude of the error and the use of these data to optimize the design of the deforming broach, the method of multifactorial planning of the experiment was applied, followed by the processing of results by regression analysis methods.

Table 2

Factors and intervals of their variation

\begin{tabular}{|c|c|c|c|c|c|}
\hline $\begin{array}{l}\text { Coded } \\
\text { factor } \\
\text { values }\end{array}$ & Factors & $\begin{array}{l}\text { Top } \\
\text { level }\end{array}$ & $\begin{array}{l}\text { Lower } \\
\text { level }\end{array}$ & $\begin{array}{l}\text { Basic } \\
\text { level }\end{array}$ & $\begin{array}{c}\text { Variation } \\
\text { interval }\end{array}$ \\
\hline$x_{1}$ & $\begin{array}{l}\text { The difference between the diameter of the } \\
\text { intermediate guide and the diameter of the last } \\
\text { roughing element is } \Delta_{1}, \mathrm{~mm}\end{array}$ & 0 & $-0,06$ & $-0,03$ & 0,03 \\
\hline$x_{2}$ & $\begin{array}{l}\text { Tension on the first finishing deforming element }-a_{l}, \\
\mathrm{~mm}\end{array}$ & 0,4 & 0,2 & 0,3 & 0,1 \\
\hline$x_{3}$ & $\begin{array}{l}\text { The difference between the diameter of the rear guide } \\
\text { and the diameter of the finishing deformation element } \\
\qquad-\Delta_{2}, \mathrm{~mm}\end{array}$ & 0 & $-0,06$ & $-0,03$ & 0,03 \\
\hline$x_{4}$ & $\begin{array}{l}\text { The ratio of the length of the intermediate guide to its } \\
\text { diameter }-L_{l} / d_{1}\end{array}$ & 2 & 0,6 & 1,3 & 0,7 \\
\hline$x_{5}$ & $\begin{array}{l}\text { The ratio of the length of the rear guide to its } \\
\text { diameter }-L_{2} / d_{2}\end{array}$ & 2 & 0,6 & 1,3 & 0,7 \\
\hline
\end{tabular}

A new series of experiments was planned for constructing an interpolation model, which would reveal the influence of each of the factors on the change in the geometric error. Five factors were varied, each experiment on the previously described blanks repeated three times. Factors and intervals for their variation are given in Table 2.

On the basis of the conducted experiments, decisions were made to approximate the functional dependence of the polynomial of the first degree of the form (3) taking into account the mutual influence of the factors:

$$
y=f=b_{0}+\sum_{i=1}^{n} b_{i} x_{i}+\sum_{i \neq j} b_{i j} x_{i} \cdot x_{j i}
$$




\section{Cylindrical Control of Holes of Tube Details Manufactured by Deforming Broaching}

where $x_{1}, x_{2}, x_{3}, x_{4}, x_{5}$ are the coded values, respectively: $\Delta_{1}, a_{1}, \Delta_{2}, L_{1} / d_{1}, L_{2} / d_{2}$.

Coding was carried out according to the formula given in [10]:

$$
x_{i}=\frac{2 \tilde{x}_{i}-\tilde{x}_{i \max }-\tilde{x}_{i \min }}{\tilde{x}_{i \max }-\tilde{x}_{i \min }},
$$

where $\tilde{x}_{i}$ - value of the encoded factor in its natural form; $\tilde{x}_{i \max }, \tilde{x}_{i \min }$ - respectively, the maximum and minimum values of the $i$-th factor in its natural form.

Mathematical processing of experimental results allowed first obtain the following regression model:

$$
\Delta y=3.41-0.063 x_{1}-0.157 x_{2}-0.102 x_{3}-0.382 x_{4}-0.543 x_{5} .
$$

It follows from the model (4) that all the factors introduced into the experimental design have a positive effect on reducing the curvature of the axis of the treated hole. But their influence is different.

The diameters of the intermediate and rear guides $\left(x_{1}, x_{3}\right)$ have the least influence. This is due to the fact that the chosen range of their variation is optimal, since it provides their robot exclusively in the zone of elastic tension. This ensures a reliable contact of the guide with the surface to be treated, and hence the efficiency of their use.

The tension on the first finishing element $\left(x_{3}\right)$ has a significant influence on the bending of the axis, and with its increase in the curvature of the axis decreases. This is confirmed by the data of the calculations performed according to the above dependence (1), which shows that with increasing tension on the element, the variation of the axial deformations of the sections of blanks of various thickness in the circumferential direction decreases.

Factors $\left(x_{4}, x_{5}\right)$ are the most significant influence on the bending of the axis of the treated hole. length of the intermediate and rear guides. In the presence of supports in the focus of deformation, the stabilizing moments relative to them, which prevent distortion (Fig. 9) and arise from the action of these guides, ensure the straightness of the axis of the machined part.

Taking into account the mutual influence of factors, and also after the omission of insignificant coefficients, dependence (4) took the following form:

$$
\begin{aligned}
& \Delta y=2.943+0.041 x_{1}-0.128 x_{2}+0.063 x_{3}-0.227 x_{4}-0.476 x_{5}-0.011 x_{1} x_{2}+0.039 x_{1} x_{3}+ \\
& +0.051 x_{2} x_{4}-0.049 x_{1} x_{3}-0.036 x_{2} x_{3}-0.082 x_{2} x_{4}-0.254 x_{2} x_{5}-0.013 x_{3} x_{4}-0.142 x_{3} x_{5}+ \\
& +0.054 x_{4} x_{5} \text {. }
\end{aligned}
$$

From the dependence (5) it follows that there is a significant mutual influence of the factors. In particular, a significant reduction in the curvature of the treated hole gives a joint influence of the factors $\left(x_{3}, x_{5}\right)$, i.e. the optimum effect of the rear guide on reducing curvature will be with increasing tension on the finishing deforming element.

Thus, the workpieces processed by the broach of the new construction satisfy the technical requirements for the part. Therefore, a new approach to its design should be used when processing the structures of deforming broaches for processing deep holes in various thickness blanks.

\section{The analysis of the influence of methods of basing on precision}

In addition, the analysis of the conducted experiments (Table 1) indicates a significant spread of the obtained values of the curvature of the axis of the manufactured parts. Therefore, it was suggested that we did not take into account the influence of one of the external factors, which distorts the axisymmetry of deformation. According to the data (Fig. 7), it is the misalignment of the tool axes and the workpiece. This factor arises in the process of processing as a result of the broaching according to the compression scheme and the diameter of the hole of the support cup, taking into account a rather significant amount of the total plastic deformation of the workpiece, was larger than the outer diameter of the workpiece after its processing. This leads to the fact that the support end of the workpiece under the influence of its weight can take an eccentric position by contacting the outer surface of the workpiece with the surface of the opening of the support cup. 


\section{Yakov Nemyrovskyi, Eduard Posvyatenko, Sergey Sheikin, Yuriy Tsekhanov}

Preliminary experiments were carried out with the processing of the above-described rounded tubular blanks with a different thickness of $1 \mathrm{~mm}$.

Prior to processing, the workpiece 1 was placed in a centring cup 2 with a gap of $1.5 \mathrm{~mm}$ and fixed with balls 3 of a ductile material, for example lead, in three schemes (Fig. 10).

Fixing schemes:

- the concentricity of the hole in the workpiece and the surface of the hole in the glass was ensured (Fig. 10, a), $\delta=0$;

- the blank with a thick wall was pressed against the surface of the glass (Fig. 10, b), (the displacement of the axis of the workpiece hole relative to the glass axis is $\delta=1.5 \mathrm{~mm}$ );

- the workpiece was pressed against the surface of the hole by a thin wall (Fig. 10, c), (the displacement of the axis of the workpiece hole relative to the glass axis is $\delta=2.5 \mathrm{~mm}$.

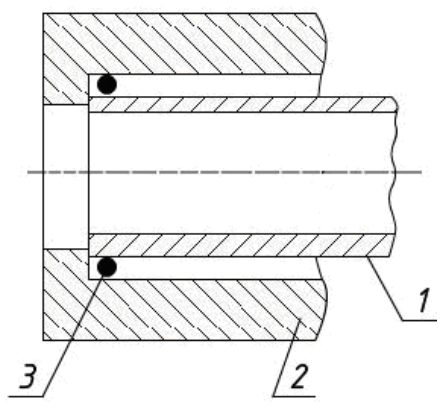

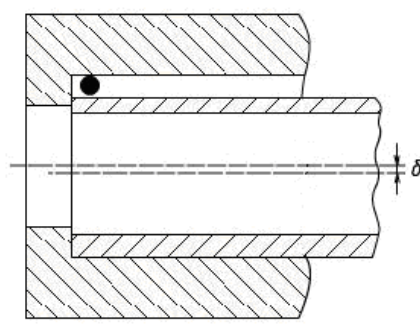

$\mathrm{b}$

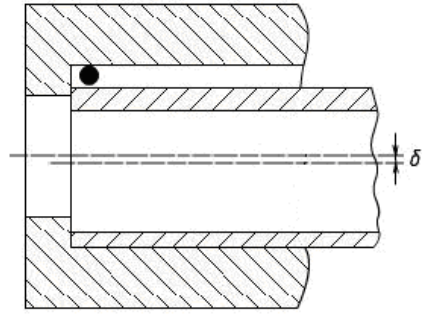

Fig. 10. Bases of the billet in the centring cup

The deformation was performed by a broach, assembled according to scheme 1, i.e. without structural elements that affect the curvature of the axis. Five baskets were stretched for each basing scheme. The average value of the curvature of the axis of the hole in the first scheme of basing is $5.4 \mathrm{~mm}$; on the second $-6.3 \mathrm{~mm}$; on the third $-7.8 \mathrm{~mm}$.

These data indicate that the misalignment of the tool and the workpiece affects the amount of curvature of the axis of the machined hole. Therefore, to obtain rectilinear parts, it is necessary to exclude misalignment of the tool and the hole of the workpiece.

\section{Improvement of the broach and its testing}

To fulfill this condition, it was decided to equip the deforming broach structure, according to the recommendations of [11], with a flat, forward guide elastic in the radial direction. The larger diameter of this guide should exceed the initial diameter of the hole of the workpiece being processed. The structural dimensions of this guide ensure the alignment of the tool and the machined hole and exclude nonaxisymmetry of deformation. This will improve the basing conditions, and therefore reduce the curvature of the axis of the hole being treated.

The test of this broach was carried out by processing a batch of blanks in an amount of 50 pieces. from cold-drawn pipe, dimensions $56 \times 4$ according to GOST 8734-75, from steel 20 according to GOST $8733-74$, length $500-4 \mathrm{~mm}$. The processing was carried out according to the scheme of compression of the broach of an improved design, based on the scheme 8 . The broach consisted of an elastic front guide, five roughing elements, an intermediate and a back guide, one finishing and a special element placed and in contact with the plastic section of the non-contact zone after a finishing deforming element. Taking into account the recommendations [8], the angle of inclination of the generator of the working cone of the finishing deforming element was taken to be $\alpha=2^{\circ}$. This was to reduce the variation of axial deformations, which directly affects the bending of the axis of the machined hole.

The processing of such a broach ensured the production of holes with dimensions $49.54 \div 49.56 \mathrm{~mm}$ with ellipticity up to $0.02 \mathrm{~mm}$. 


\section{Cylindrical Control of Holes of Tube Details Manufactured by Deforming Broaching}

The curvature of the axis of the manufactured parts was controlled by a caliber with a diameter of $49.05 \mathrm{~mm}$, which ensured free passage of parts with a curvature of the axis $f \leq 0.5 \mathrm{~mm}$. All processed parts passed through this caliber freely. We had an additional caliber with a diameter of $49.15 \mathrm{~mm}$, which provided free passage of parts with $f \leq 0.4 \mathrm{~mm}$. All processed parts also passed freely through this caliber.

Thus, testing a new design of the deforming broach has shown that it allows to solve the problem of successful processing of different thickness blanks of considerable length.

The conducted researches formed the basis for the development of deforming broaching structures for processing deep holes in tubular parts at the factories of Ukroboronprom.

\section{Conclusions}

Based on the study of the regularities of material flow in the deformation region and changes in the axial deformations of the processed blanks, a new scientifically grounded approach for the design of deforming broach constructions is proposed, which allows to control the cylindricality of the processed deep holes of tubular blanks.

It is shown that the growth of misalignment of the tool and the workpiece increases the curvature of the axis of the processed hole.

An effective method for eliminating misalignment of the tool and workpiece due to improved basing from the inner surface of the part is proposed.

\section{References}

[1] A.M. Rozenberh, O.A. Rozenberh, E.Y. Hrytsenko, and E.K. Posvyatenko, Kachestvo poverkhnosty, obrabotannoy deformyruyushchym protyahyvanyem [Quality of the surface treated by deforming broaching]. Kyiv, Ukraine: Naukova Dumka Publ., 1977, 188 p. [in Russian].

[2] Yu. A. Tsekhanov, and S.E. Sheikin, Mekhanika formoobrazovaniya zagotovok pri deformiruyushchem protyagivanii [Mechanics of workpiece shape-generating at deforming broaching]. Voronezh, Russia: Voronezh State Technological Academy, 2001, 200 p. [in Russian].

[3] Yu.G. Proskuryakov, V.N. Romanov, and A.N. Isaev, Ob'emnoe dornovanie otverstiy [Volumetric turfing of holes]. Moscow, Russia: Mashinostroenie Publ., 1984, 223 p. [in Russian].

[4] A.M. Rozenberg, O.A. Rozenberg, and D.A. Sirota, Tverdosplavnye protyazhki dlya obrabotki otverstiy metodom plasticheskogo deformirovaniya [Hard alloy metal broaching for forming with plastic deformation]. Kyiv, Ukraine: UkrNIITI, 1968, 40 p. [in Russian].

[5] O.A. Rozenberg, Mekhanika vzaimodeystviya instrumenta s izdeliem pri deformiruyushchem protyagivanii [Mechanics of interaction between the tool and the product at deforming broaching]. Kyiv, Ukraine: Naukova Dumka Publ., 1981, 288 p. [in Russian].

[6] Ya.B. Nemirovskyi, "Naukovi osnovy zabezpechenya tochnosti pri deformuyuchomu protyaguvanni" ["Scientific principles ensure accuracy when deforming broaching"]. Sc.D. dissertation, National Technical University of Ukraine "Igor Sikorsky Kyiv Polytechnic Institute", Kyiv, Ukraine, 2018. [in Ukrainian].

[7] Yu.A. Tsekhanov, Ya.B. Nemirovsky, "Vliyanie tehnologicheskih parametrov deformiruyuschego protyagivaniya na konechnie deformacii zagotovok" ["Influence of the technological parameters of the deforming broaching on the final deformation of blanks"]. in High technologies in mechanical engineering. Kharkiv, Ukraine: Kharkiv State Polytechnical University, 2000, pp. 281-285. [in Russian].

[8] Ya.B. Nemirovskyi, A.I. Gerovsky, "Krivizna osi raznotolschinnih zagotovok obrabotannih deformiruyuschim protyagivaniem" ["The curvature of the axis of different thickness blanks processed by deforming broaching"], Tekhnika $v$ silskohospodarskomu vyrobnytstvi, haluzeve mashynobuduvannia, avtomatyzatsiia [Engineering in agricultural production, branch engineering, automation], no.14, pp. 222-229, 2004. [in Russian].

[9] Ya.B. Nemirovskyi, "Tehnologicheskoe obespechenie tochnosti pri obrabotke otverstii deformiruyuschim protyagivaniem" ["Technological provision of precision in the treatment of holes by deforming broaching"], Rezanie $i$ instrument $v$ tekhnologicheskikh sistemakh [Cutting and the tool in technological systems], vol. 83, pp. 195-207, 2013. [in Russian].

[10] F.S. Novik, Matematicheskie metody planirovaniya v metallovedenii [Mathematical methods of planning in metallurgy]. Moscow, Russia: Moscow Institute of Steel and Alloys, 1972, 106 p. [in Russian].

[11] Ya.B.Nemirovskyi, etc. "Zbirna deformuyucha protyazhka" ["Collected deforming broach"], UA Patent 124157, March 26, 2017. [in Ukrainian]. 